\title{
ПАРАДИГМЫ И ОППОЗИЦИИ \\ СОВРЕМЕННОЙ ДЕМОГРАФИИ
}

\section{МихАИЛ КЛУПТ}

\begin{abstract}
Цель статьи - способствовать развитию демографической теории путем методологической рефлексии. Рассматриваются три важнейших оппозиции современной демографической теории: Запад и остальной мир; государство и индивид; долгосрочные и краткосрочные тренды. Приведены аргументы в пользу превращения демографии из монопарадигмальной в мультипарадигмальную науку, подобную соииологии. Ставятся под сомнение широко распространенные в демографии воззрения: уход государства $c$ демографической арены и распространение второго демографического перехода за пределы стран Запада. Показано, что успехи и неудачи государства в Индии, Индонезии, Китае и Нигерии оказали значительно больщее влияние на численность и географическое распределение населения мира, чем второй демографический переход в странах Запада. Обнаружена тесная обратная корреляция между ожидаемой продолжстельностью жизни при рождении и долей внебрачных рождений в регионах. Это свидетельствует о том, что внебрачная рождаемость в России является не только результатом второго демографического перехода, но также, в значительной степени, следствием различных социальных патологий. Понятие governmentality, введенное Фуко, используется для того чтобы показать, что различные типы governmentality приводят к различным типам демографической политики; подобная трактовка отличается от интерпретаиии Гринхал, обративщей внимание на западные корни китайской политики одного ребенка. Подчеркивается, что демографии следует уделять больше внимания специфике государства в различных незападных странах и эффектам, возникающим при взаимодействии «иенностей второго демографического перехода» и незападных институтов.
\end{abstract}

Ключевые слова: демографическое развитие; множественность современностей; второй демографический переход; государство; governmentality; демографическая политика.

Статья представляет собой попытку оценить современное состояние демографической теории и перспективы ее развития. Демография, по справедливому замечанию Д. Кирка, представляет собой науку «скупую на теории, но богатую на квантификации» [Kirk 1996: 361]. Однако, несмотря на преимущественно эмпирический характер демографии, анализ ее парадигмальных оснований актуален, ибо в науке господствующая парадигма всегда направляет эмпирические исследования по определенному пути и делит данное научное сообщество на «своих» и «чужих» - тех, кто укладывается и не укладывается в заданные парадигмальные рамки.

МИХАИЛ АЛЕКСАНДРОВИЧ КЛУПТ. ГУМАНИТАРНЫЙ ФАКУЛЬТЕТ САНКТ-ПЕТЕРБУРГСКОГО ГОСУДАРСТВЕННОГО ЭКОНОМИЧЕСКОГО УНИВЕРСИТЕТА. РОССИЯ. Е-MAIL: klupt@mail.ru. СТАТЬЯ ПОСТУПИЛА В РЕДАКЦИЮ В ЯНВАРЕ 2014 Г. 
В отличие от большинства работ на названную тему данная статья в известной степени представляет собой взгляд на демографию извне, ибо демографическая теория сравнивается в ней с недемографическими теориями и практиками. Главное внимание уделяется при этом сравнению подходов к фундаментальным оппозициям обществознания: государство и индивид; современность и традиционность; Запад и не Запад; малое и большое время. Конечная цель подобного анализа - способствовать развитию демографии путем методологической рефлексии, разумеется, едва ли достижима в полной мере в рамках одной статьи.

\section{СКОЛЬКО ПАРАДИГМ НУЖНО ДЕМОГРАФИИ?}

Научные статьи, как известно, можно писать по-разному. Можно развертывать изложение постепенно, интригуя читателя, словно в детективе, и только в заключении сообщить ему вывод из всего написанного и прочитанного. Можно, напротив, начинать с ключевого тезиса, постепенно раскрывая его, обосновывая и демонстрируя нюансы и оттенки. Выберем второй путь.

Как представляется, в современных социальных науках сосуществуют, далеко не всегда мирно, две основополагающие парадигмы. Их развернутое описание вряд ли необходимо, ибо для понимания специалистом того, о чем идет речь, достаточно набора ключевых слов. Первую парадигму характеризуют: формационный или стадиальный подход; западоцентризм, тезис о том, что современность (modernity) едина и неделима; уверенность в том, что государство все меньше и меньше влияет на социальные процессы, а социальный контроль над индивидом уходит в прошлое. Для второй парадигмы характерны: цивилизационный подход; тезис о множественности современностей (multiple modernities); понимание растущей роли незападных обществ в современном мире; предположение о том, что государство еще не сказало своего последнего слова, а социальный контроль над индивидом никуда не делся - он просто принял, да и то не везде, более изощренные формы.

Автору статьи ближе вторая парадигма, но лишь до известных пределов. Как представляется, жесткое следование лишь одной из двух названных парадигм препятствует развитию любой науки, включая демографию. Оптимальной же для ее развития является мультипарадигмальность. Мультипарадигмальность или, точнее, бипарадигмальность, ибо рассматриваемых парадигм всего две, в свою очередь предполагает некоторую пропорцию, баланс между ними.

С точки зрения автора, в современной социологии баланс между парадигмами ближе к оптимальному, чем в демографии. Социология действительно мультипарадигмальна, в демографии же первая из названных парадигм (стадиальный подход, западоцентризм, акцент на единстве современности, ослаблении государства и усилении автономии индивида от пут социального контроля) выражена значительно сильнее, чем вторая. Подобный характер демографии препятствует адекватному отражению места незападных государств в глобализационных процессах и взаимодействия Запада и не Запада. Впрочем, до известной степени «западоцентризм» современной демографии смягчается 
преимущественно эмпирической направленностью демографии, заметно ослабляющей парадигмальные тиски. Таковы основные тезисы статьи, дальнейшее - их развертывание, нюансировка и обоснование. Памятуя о долгой истории упомянутого межпарадигмального спора, мы остановимся, главным образом, на рассмотрении его новейших витков.

\section{СКОЛЬКО СОВРЕМЕННОСТЕЙ В СОВРЕМЕННОМ МИРЕ?}

Парадигма однолинейного развития способствует продвижению в познании мира в тех случаях, когда рассматриваемые процессы или объединяющий их суммарный тренд однонаправлены. Для исследования причин разнонаправленности процессов, различий в развитии географических, социальных, культурных и других сегментов мира парадигмы однолинейного развития недостаточно. Поэтому поток произведений, акцентирующих внимание на однолинейности развития, - политическая транзитология образца 1990-х годов, «Конец истории» Ф. Фукуямы [2004] и др., сразу же порождает ответную теоретикометодологическую волну. В конце 1990-х - начале 2000-х годов ее наиболее ярким проявлением стала теория множественности современностей (multiple modernities).

Спор о числе современностей, развернувшийся в минувшем десятилетии, может, на первый взгляд, показаться схоластическим, что в немалой степени связано с трудностями перевода термина multiple modernities ${ }^{1}$. В действительности, однако, речь идет о новом витке теоретической полемики между представителями двух школ - всемирноисторической и цивилизационной. Стимулом к ее продолжению, как это часто бывает, стал новый виток истории и его характерные черты: успехи китайской и индийской модернизации, выход на политическую авансцену исламского фундаментализма, события на постсоветском пространстве.

Открывая выпуск журнала «Дедалус», посвященный теории множественности современностей (multiple modernities), Ш. Эйзенштадт подчеркивает, что это понятие «обозначает определенный взгляд на современный мир, более того, на всю историю нового времени и его базовые характеристики - взгляд, противоречащий воззрениям, превалирующим на протяжении долгого времени в научном и общем дискурсе. Этот взгляд идет в разрез с теориями модернизации и конвергенции индустриальных обществ, преобладавшими в 1950-е годы, и более того, с классическим социологическим анализом Маркса, Дюркгейма и даже (в значительной степени) Вебера... Все они полагали, порой неявно, что культурная программа современности и ее базовые системы институтов, развившиеся в Европе, уже приняли свою окончательную форму во всех модернизированных и модернизирующихся обществах и что по мере вытеснения

\footnotetext{
${ }^{1}$ В действительности, эти трудности демонстрируют двойственность того, что понимается под modernity. C одной стороны, modernity - это время, в котором (неважно, как и в каких условиях) мы живем. С другой, это период развития общества, для которого характерен определенный набор свойств (каких именно - отдельный вопрос). Подобная двойственность открывает простор для различных интерпретаций. Одни авторы полагают, что часть человечества живет сегодня в досовременности, часть в современности, а часть - в постсовременности. Другие предпочитают говорить о «множестве современностей» или, напротив, о вариациях одной современности.
} 
несовременного современным именно эта форма современности будет превалировать во всем мире» [Eisenstadt 2000: 1].

Близкую позицию занимает и Б. Виттрок. По его мнению, «множество технологических, экономических и политических институтов, появившихся в определенной ситуации в Западной Европе, распространились по миру, иногда лишь в качестве идей, а в некоторых случаях и в качестве осязаемой реальности. Однако эти процессы диффузии и адаптации вовсе не означают, что глубокие культурные и космологические различия между, скажем, Западной Европой, Китаем и Японией вот-вот исчезнут. Это означает лишь, что различным культурным единицам приходиться адаптироваться к совокупности распространившихся по всему миру идей и практик» [Wittrok 2000: 54-55].

H. Музелис [Mouselis 1997] привлекает для описания социально-исторического механизма, порождающего разнообразие обществ, схему $\mathrm{AGIL}^{2}$ (адаптация, целедостижение, интеграция, сохранение латентного образца), разработанную в середине прошлого века Т. Парсонсом [1998]. Музелис подчеркивает возможность различных вариантов субординации ее составных элементов. По его мнению, модернизации в Китае, Японии и странах Юго-Восточной Азии представляют собой примеры более или менее выраженного доминирования высокоадаптивной экономики и традиций, обеспечивающих интеграцию общества, над либеральными ценностями и демократическим представительством. Возможны и такие варианты модернизации, при которых "сохранение латентного образца" (например, религиозных традиций) подчиняет себе остальные сферы жизни общества (Иран) и т.д.

По мнению А. Мартинелли [2006: 181], «Маркс, Вебер и Дюркгейм (а также послевоенные теоретики) в своих классических теориях модернизации явно или неявно преувеличивают степень синхронности развития различных измерений модернизации... Однако сторонники идеи нескольких современностей преувеличивают уровень разрозненности процессов модернизации».

Теория множественности современностей, разумеется, не ставит точку в споре между сторонниками всемирно-исторического и цивилизационного подходов. Критика этой теории не заставила себя долго ждать: Ф. Шмидт [Schmidt 2006] полагает, например, что в действительности имеет место не множественность современностей, а вариация внутри одной современности. В демографии близкую позицию на протяжении многих лет занимает А.Г. Вишневский (например [Вишневский 2012]).

Имеет ли, впрочем, теория множественности современностей какое-либо касательство к демографической теории? Как представляется, самое непосредственное. Ведь если современностей не одна, а несколько, то фундаментальное для демографии понятие демографического перехода, понимаемого как движение из точки $T$ (традиционное общество) в точку $M$ (современное общество) оказывается плохо определенным. Появляется необходимость уточнить, в какую из точек $M_{1}, M_{2}, \ldots, M_{n}$, обозначающих

\footnotetext{
${ }^{2}$ Аббревиатура от adaptation, goal attainment, integration, latency.
} 
современности 1-го,.., n-го типа, происходит переход. Так, Нигерия, с ее суммарным коэффициентом рождаемости (СКР) 5,6 оказывается в этом случае не страной, находящейся на начальной стадии демографического перехода, а страной, перешедшей из традиционного общества в другую - отличную от европейской, китайской и т.д. современность. В этой современности есть буровые вышки, выборы, хотя и несколько отличные от тех, что проводятся в западных странах, скорострельное автоматическое оружие, мобильные телефоны и джинсы, однако рождаемость остается высокой.

Столь же методологически неопределенным оказывается и понятие второго демографического перехода. Вспомним «агностический комментарий» Коулмена: «это не переход, потому что отсутствует всеобщее движение из одной точки в другую» [Coleman 2004]. С точки зрения теории множественности современностей, речь, скорее, идет не о переходе, а о некотором наборе перемещений между современностями различного типа, причем априори неизвестно, насколько вообще упорядочен этот набор. Рассмотрим данный вопрос более подробно

\section{СУЖАЕТСЯ ИЛИ РАСШИРЯЕТСЯ ВСЕЛЕННАЯ ВТОРОГО ДЕМОГРАФИЧЕСКОГО ПЕРЕХОДА?}

Д. ван де Каа, разработавший вместе с Р. Лестегом теорию второго демографического перехода [Lesthaeghe, van de Каa 1986], подчеркивает, что второй демографический переход отличает от первого “ошеломляющее стремление к самореализации, свободе личного выбора, личностному развитию и эмансипации, что отражается в формировании семьи, установках относительно регулирования рождаемости, мотивации родительства. Растущие доходы, экономическая и политическая безопасность, которые демократические государства благосостояния обеспечивают своим жителям, запускают спусковой механизм «бесшумной революции»; происходит сдвиг в направлении «масловианского постматериализма», при котором сексуальные предпочтения принимаются такими, какие они есть, а вступление во внебрачный союз, аборты, стерилизация или добровольная бездетность в большинстве случаев оставляются на усмотрение индивидов или их пары» [van de Kaa 1996: 425].

По мнению Р. Лестега [Lesthaeghe 2010: 44], «второй демографический переход может охватывать не только западные общества.... В число стран, охваченных вторым демографическим переходом, вошли несколько авангардных азиатских населений, в которых наблюдаются все характерные черты второго перехода за исключением одной внебрачной рождаемости... Как хорошо известно, средства массовой информации продуцируют глобальную культуру, в которой видное, если не доминирующее положение занимают личная автономия и самореализация, мотивирующие и оправдывающие второй демографический переход. Разумеется, ответная политическая, религиозная и идеологическая реакция (например, со стороны христианского или мусульманского фундаментализма) всегда возможна, но до сих пор в странах с демократическим правлением она не была настолько сильной, чтобы заставить ценности второго демографического перехода отступить». 
Однако обстоит ли дело именно так, как полагает Лестег? Действительно ли вселенная второго демографического перехода расширяется и в него постепенно включается все большее число мужчин и женщин по всему миру? Подобное утверждение вызывает сомнение по следующим причинам.

1. Численность населения развивающихся стран растет гораздо быстрее, чем развитых. При этом наиболее быстрый демографический рост происходит в беднейшем регионе мира - тропической Африке. Большинство жителей развивающихся стран, в отличие от жителей развитых государств, по-прежнему озабочено удовлетворением базовых потребностей, лежащих в основании пирамиды Маслоу. Формирование в развивающихся странах упоминаемых Д. ван де Каа «демократических государств всеобщего благосостояния (democratic welfare states)» западного образца в силу экономических, политических и культурных причин в обозримом будущем вряд ли возможно. Даже в Китае, где уровень благосостояния быстро растет, говорить о начале второго демографического перехода неправомерно, поскольку там по-прежнему существует система административных ограничений рождаемости. Говорить о втором (а не первом) демографическом переходе в целом ряде регионов с относительно низким уровнем рождаемости - таких, например, как индийские штаты Керала и Тамилнаду, также нет оснований. Причина - бедность, исключающая сколько-нибудь массовый переход к «постматериалистическим» ценностям, доминирующим, по мнению ван де Каа и Лестега, в развитых странах Запада ${ }^{3}$.

2. В странах Запада число иммигрантов из развивающихся стран растет быстрее, чем население в целом, а темпы интеграции иммигрантов в принимающие общества отстают от темпов роста их числа. Так, численность населения США между переписями 2000 и 2010 гг. выросла на 9,8\%, тогда как число иммигрантов мексиканского происхождения - на 54,1\% [U.S. Census Bureau 2011: 4]. При этом коэффициенты представленности испаноговорящих американцев в занятиях составляют: менеджеры 0,52, рабочие строительства и промышленности 2,03, рабочие строительства и транспорта $1,47 .{ }^{4}$ Во Франции уровень безработицы среди мужчин - выходцев из Алжира в первом поколении составлял $16 \%$, во втором - 20\%; для выходцев из Марокко и Туниса значения того же показателя составили соответственно 12 и 22\% [Trajectoires et Origines 2010: 56]. Население Англии и Уэльса выросло между 2001 и 2009 гг. на 4,1\%, тогда как число иммигрантов из тропической Африки - на 61,4\%, при этом в 4-м квартале 2010 г. уровень безработицы среди белых британцев составлял 7,1\%, среди иммигрантов из тропической Африки - 18,1\% [Office for National Statistics 2011a, 2011b: Table A09].

\footnotetext{
${ }^{3}$ Например, среднедушевой ВВП в штате Керала примерно на треть выше значения аналогичного показателя для Индии. Последний при оценке по паритету покупательной способности (ППС) составляет 3,8 тыс. долл. Таким образом, даже при оценке по ППС среднедушевой ВВП в Керале составляет лишь 10 - $20 \%$ от среднедушевого дохода, типичного для развитых стран зарубежной Европы [World Bank 2013; The Indian States and Territories 2013].

${ }^{4}$ Коэффициент представленности меньшинства в занятии рассчитывается как соотношение долей данного меньшинства среди лиц, имеющих данное занятие, и во всем занятом населении в возрасте 16 лет и старше. Рассчитано по: [Bureau of Labor Statistics]. Более подробный анализ вопроса см. в [Клупт 2012].
} 
3. В развитых странах, наряду с иммигрантами, существует и ряд других групп, которые спустя почти четыре десятилетия после начала второго демографического перехода так и не включились в него и, более того, иногда настроены по отношению к лежащим в его основе «нонконформистским ценностям» весьма агрессивно. В США к ним относятся христианские фундаменталисты, движение prolife и, шире - белые консерваторы, составляющие ядро электората республиканской партии. В [Lesthaeghe, Neidert 2006; 2009] статистически подтверждена корреляция между отношением к ценностям второго демографического перехода и голосованием за того или иного кандидата на президентских выборах.

4. В России наблюдается сильная отрицательная корреляция между ожидаемой продолжительностью жизни при рождении и долей внебрачных рождений; в Москве и Санкт-Петербурге эта доля ниже, чем по стране в целом (рисунок 1). Иными словами, внебрачная рождаемость наиболее высока в социально неблагополучных регионах и, в значительной степени, связана с алкоголизмом и делинквентным поведением (подробнее см. [Клупт 2010]). В последние годы доля внебрачных рождений повсеместно снижается. Все это свидетельствует о том, что рост внебрачной рождаемости в России в 1990-е годы был в значительной степени вызван социальной патологией и экономическими трудностями, а не вторым демографическим переходом.

5. В ряде авангардных стран Азии - Японии, Южной Корее, а также странах ЮгоВосточной Европы со значительной долей православного или мусульманского населения, имеет место скорее появление гибридных феноменов, чем второй демографический переход в его западном понимании. Наиболее очевидным, хотя и не единственным подтверждением этого является незначительная доля внебрачных рождений в их общем числе.

6. До настоящего времени не вполне ясен вопрос, насколько одинаково понимаются «нонконформистские» ценности, о которых говорит Лестег, представителями разных культур, да и просто более и менее законопослушных групп населения. По мнению Д. Шека, «базовый вопрос состоит в том, насколько западные теории и результаты исследований, основанные прежде всего на индивидуалистических ценностях, применимы к китайским семьям, которые руководствуются прежде всего коллективистской идеологией» [Shek 2006: 279].

7. В сущности, бесспорное включение во второй демографический переход крупных регионов, в которых он ранее был слабо выражен, наблюдалось в последнем десятилетии лишь в Северной (но не Южной) Италии [Castiglioni, Dalla Zuanna 2009] и Испании, где доля внебрачных рождений выросла с 17,7\% в 2000 г. до 34,5\% в 2011 г. 


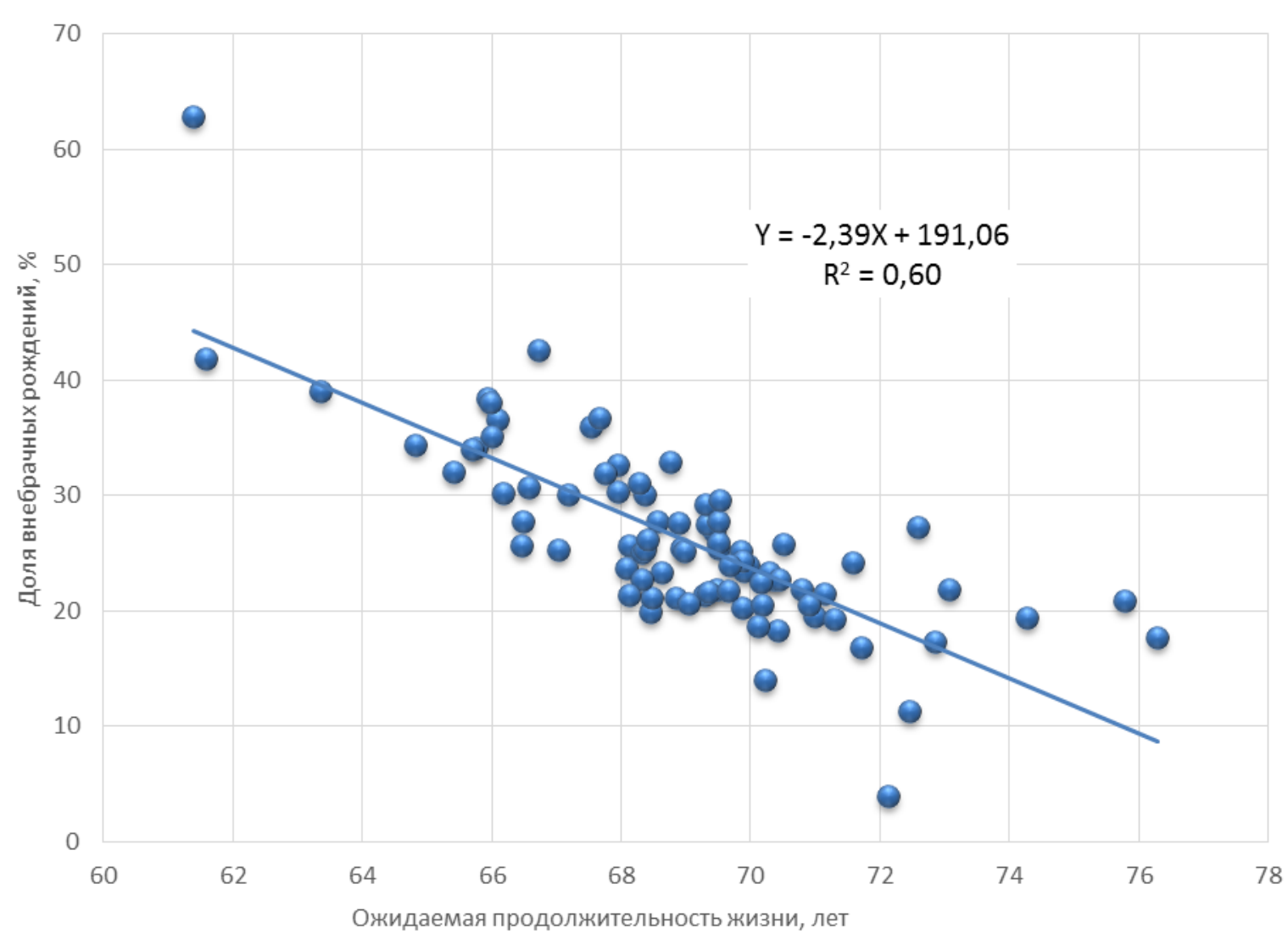

\section{Рисунок 1. Обратная зависимость между ожидаемой продолжительностью жизни при рождении и долей внебрачных рождений в субъектах Федерации в России в 2011 г.}

Как представляется, доминирование парадигмы однолинейности приводит к неверной расстановке акцентов при изучении второго демографического перехода. Главное внимание уделяется спору о том, охватил или нет второй демографический переход тот или иной регион и, шире, является ли он региональным или глобальным феноменом. На мой взгляд, доля населения планеты, включенного во второй демографический переход в его узком «западноевропейском» определении, не увеличивается, а падает. В этих условиях наибольший интерес представляют специфические эффекты, возникающие при проникновении «постматериалистических» ценностей в незападные культуры. При таком подходе крайне низкие показатели внебрачной рождаемости в странах Восточной Азии представляют не исключение, а часть закономерности, в соответствии с которой процесс при переходе из одного общества в другое преломляется сквозь линзу его институциональной структуры (подробнее см. [Клупт 2008; 2010]).

\section{ГОСУДАРСТВО И ИНДИВИД}

К числу негативных последствий доминирования в демографии парадигмы однолинейности относится и односторонняя трактовка роли государства в новейшей демографической истории. В классической теории демографического перехода государство если и присутствует, то «за кадром». В теории второго демографического перехода роль государства специально не рассматривается, однако подразумевается, что по мере того, как 
главной фигурой на демографической сцене становится индивид, роль государства постепенно сходит на нет.

В действительности, однако, роль государства в новейшей демографической истории весьма велика. Его сила в одних регионах мира (прежде всего, Китае и Индонезии) и бессилие в других (яркий пример - Нигерия), а также множество комбинированных вариантов (Индия, Россия и ряд других стран) оказывали в течение минувшей половины века значительное воздействие на демографическое развитие. Скорее всего, это воздействие будет весьма ощутимым и в обозримом будущем. Рассмотрим вопрос в региональном разрезе.

\section{Крупнейшие страны Азии и Африки}

Информационный обмен между Западом и Востоком (под последним в данном контексте понимаются прежде всего азиатские общества) асимметричен. Речь идет не о банальной «утечке мозгов», а о более глубоких процессах. Запад изучает Восток научно - как эмпирически, так и теоретически. Восток отвечает асимметрично - он перенимает западные технические и технологические новшества и перекраивает, часто весьма радикально, западные социально-политические идеи, адаптируя их к нуждам собственной практики, но при этом не стремится к созданию теоретической картины Запада - последнюю, в случае необходимости, заменяют плакатные идеологические образы.

Подобная асимметрия привела к своеобразному парадоксу - основные события демографической истории второй половины XX века происходили на Востоке (точнее, не в странах Запада), а их теоретическую картину рисовал Запад. Последнему, как представляется, не удалось при этом избежать европоцентризма, в чем, впрочем, нет ничего необычного: этноцентризм в той или иной степени свойствен любому национальному видению мира - вспомним ту же китайскую «Срединную империю». Европейских исследователей, работавших в парадигме второго демографического перехода, не слишком интересовали демографические триумфы и фиаско государства в дальних странах, их вдохновлял дух Парижа 1968-го года и «демократический транзит» (или то, что этим транзитом казалось). Между тем, современное, да и будущее распределение численности населения между крупнейшими регионами мира очерчивали события на других континентах - в Азии и Африке.

Исследование новейшей демографической истории Китая, Индии, Индонезии и Нигерии, стран, в которых в настоящее время сосредоточено 43\% населения Земли, немыслимо без анализа отношений государства и индивида в этих государствах. Значительный интерес с этой точки зрения представляют работы С. Гринхал [Greenhalgh 2003; Greenhalgh, Winkler 2005], и Дж. Макниколла [McNikoll 2009; 2011]. Суммируя причины, по которым разрыв между показателями рождаемости в Нигерии и Индонезии (в настоящее время СКР в этих странах составляют соответственно 5,6 и 2,5) столь велик, Макниколл [McNikloll 2009] приходит к лаконичной формуле: «историческое наследие, политика, обстоятельства» (legacy, policy, circumstances).

В Индонезии демографическая политика стала важным составным элементом нового курса генерала Сухарто, пришедшего к власти после подавления им в 1965 г. неудачной 
попытки военного переворота. В отличие от своего предшественника Сукарно, по мнению которого богатая природными ресурсами Индонезии не нуждалась в политике, направленной на снижение рождаемости, президент Сухарто считал такую политику необходимой. Новая власть сумела подключить к программе снижения рождаемости региональную бюрократию, найти стимулы для активного участия в ней деревенских общин и убедить мусульманское духовенство не противодействовать политике правительства [Barnwall 2004]. Важную роль в проведении демографической политики сыграл также унитарный характер государства, обеспечивавший жесткую вертикаль власти и подчинение региональной бюрократии центральной.

В Нигерии, в силу ее этнического и религиозного многообразия, устройство государства является федеративным. Регионы страны конкурируют за политическое влияние и ресурсы, распределяемые центральным правительством, и в силу этого заинтересованы в большей численности населения. Слабость государства выражается, среди прочего, в неспособности провести перепись населения, итоги которой признавались бы во всех частях страны. Череда военных переворотов, постоянные конфликты на религиозной и этнической почве не позволяют проводить эффективную демографическую политику.

Как Макниколл, так и Гринхал подчеркивают, что историческое наследие не является застывшим монолитом, оно включает в себя как более, так и менее подвижные элементы. Гринхал [Greenhalgh 2003] исследует рождение и последующую эволюцию китайской демографической политики, опираясь на понятие gouvernementalité, введенное в оборот французским философом М. Фуко в конце 1970-х годов [Фуко 2003]. Это понятие, среди прочего, охватывает характерные для властей данного государства способы формулирования проблем и их решения. Гринхал приходит к выводу, что китайская демографическая политика формировалась в свое время под влиянием идей римского клуба, хотя, в силу идеологических табу, об этом не говорилось вслух. По её мнению, эволюция демографической политики КНР представляет собой постепенное движение от мобилизационных компаний, свойственных маоистскому периоду китайской истории, к неолиберальной политике западного образца, при которой контроль над индивидом (в том числе и в демографической сфере) переходит от государства к рынку.

\section{Европейский Союз}

Взгляд на роль государства в регулировании демографических процессов, господствующий в странах ЕC, хорошо известен - там предпочитают говорить не о демографической, а о семейной политике. Тем не менее, различия в национальных моделях государства благосостояния (welfare state) между странами ЕС остаются весьма заметными и оказывают определенное влияние на рождаемость. Наиболее низкий уровень рождаемости наблюдается в Южной Европе, немецкоязычных странах, а также государствах, ранее входивших в СССР или советский блок (рисунок 2). Южноевропейская модель социальной политики всегда была менее щедрой по сравнению со скандинавской, французской и британской, а страны, недавно вошедшие в ЕС, существенно отстают от его 
старожилов по уровню жизни 5 .

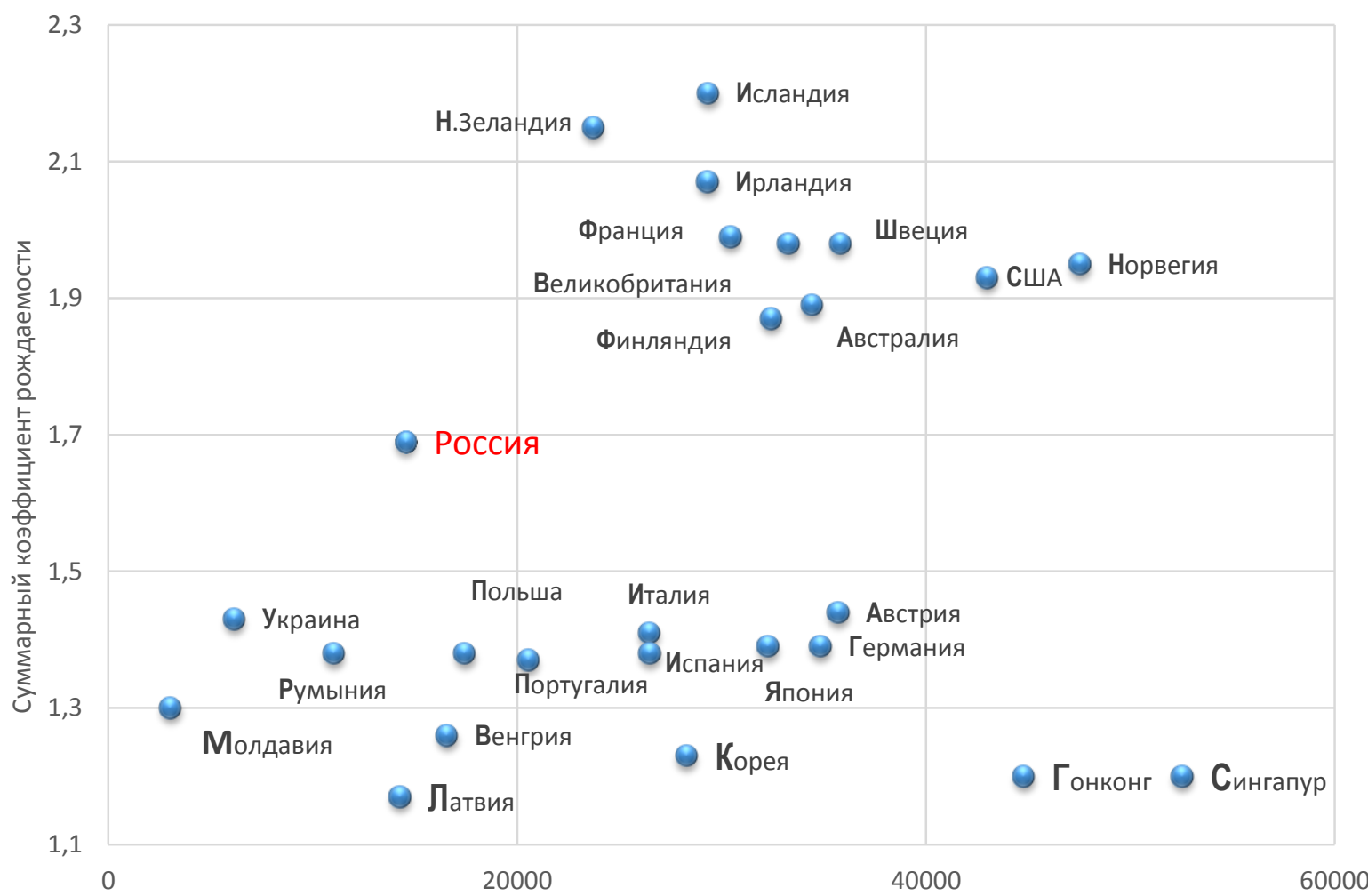

Валовой национальный доход на 1 жителя по ППС, долл.

\section{Рисунок 2. Полюса рождаемости в современном развитом мире (страны с СКР менее 1,45 и более 1,85 ) и Россия}

Это, в частности, иллюстрирует случай Германии - здесь, по всей вероятности, сыграл свою роль ряд факторов, связанных с послевоенной эволюцией немецкого социального государства. В условиях послевоенной денацификации Германии проведение пронаталистской демографической политики было невозможным, поскольку выглядело бы как продолжение демографической политики фашизма. Кроме того, социальная политика немецкого государства была ориентирована на модель семьи, в которой отец семейства был добытчиком, а мать - домохозяйкой. Как выяснилось впоследствии, эта модель оказалась менее благоприятной для рождаемости, чем французская модель, включающая (ранее явно, сейчас имплицитно) материальное поощрение рождаемости и развитую систему детских дошкольных учреждений. Эмпирическим подтверждением этого является то, что на протяжении всего периода после окончания Второй мировой войны рождаемость во Франции была выше, чем в Германии (рисунок 3).

\footnotetext{
5 Подчеркнем, что в данном случае речь идет о влиянии государственных институтов на рождаемость, а не о характере корреляции между уровнем среднедушевого валового национального дохода и рождаемостью. Вследствие такого влияния, а также ряда других факторов, достижение определенного порога ВНД на 1 жителя оказывается необходимым, но не достаточным для достижения относительно высокого по меркам развитых стран уровня рождаемости.
} 


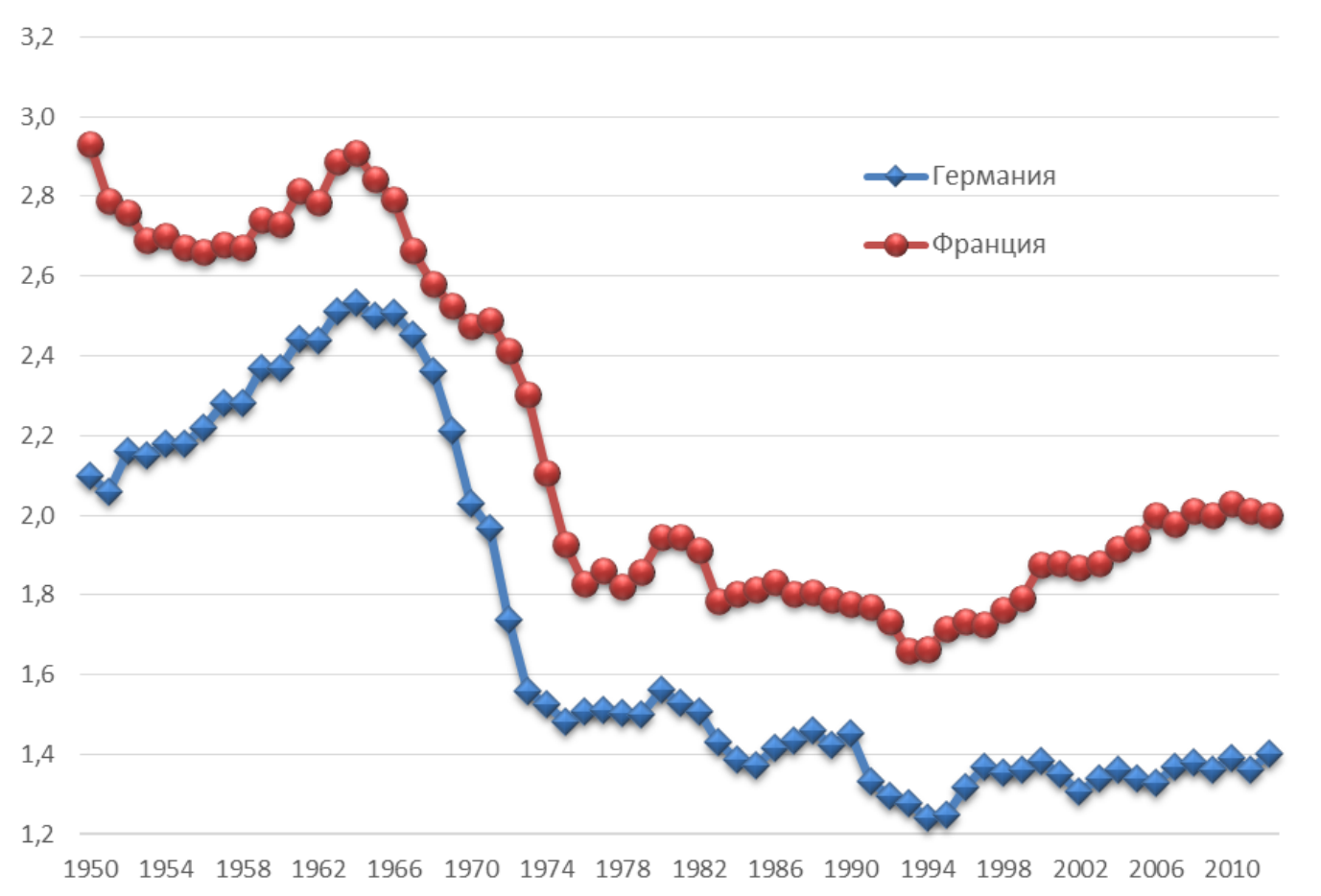

Рисунок 3. Суммарный коэффициент рождаемости во Франции и Германии в 1950-2012 гг.

Источник: Демоскоn-Weekly. URL: http://demoscope.ru/weekly/app/app4007.php

(дата обращения 29.09.2013)

\section{Россия}

Российский вариант участия государства в демографической сфере отличается от рассмотренных выше и характеризуется следующим.

1. Подавляющее большинство россиян (86\% в 2006 г. и 81\% в 2011 г.), судя по опросам фонда «Общественное мнение» [Ситуация... 2011], считает, что государство должно осуществлять меры, направленные на повышение рождаемости, однако эти меры не должны включать запрет абортов.

2. Ответственность за неблагоприятную демографическую ситуацию в стране большинство населения также возлагает на государство.

3. Большинство политиков, учитывая настроения электората, выступает (по крайней мере, публично) за меры, направленные на повышение рождаемости.

4. Основным ограничителем демографической политики выступают бюджетные ресурсы, объем которых существенно зависит от величины экспортных поступлений. Ввиду этого активная демографическая политика как в СССР, так и в современной России, до настоящего времени разрабатывалась и осуществлялась в периоды высоких мировых цен на нефть и затухала по мере их снижения (подробнее см. [Клупт 2013]).

5. Федеральный бюджет и Пенсионный фонд РФ играют в финансировании демографической политики большую роль, чем бюджеты нижестоящих уровней. Российская демографическая политика в этом отношении также имеет много общего с советской. 
6. Федеральные органы власти поощряют мероприятия региональных властей, направленные на повышение рождаемости и финансируемые из региональных бюджетов. Демографическая ситуация в регионах рассматривается федеральными властями как один из показателей эффективности деятельности региональных властей.

7. Число российских НКО, активных в вопросах демографической и семейной политики, весьма значительно, однако эти организации малы и, в лучшем случае, обладают правом совещательного голоса.

8. Как в СССР, так и в современной России вслед за введением мер демографической политики последовал существенный рост числа родившихся.

\section{Перспективы}

В обозримом будущем вряд ли стоит ожидать ухода государства с демографической сцены. В Китае в его руках остаются два мощных инструмента регулирования демографических процессов - система административных ограничений рождаемости и система прописки (хукоу). Именно от государства зависит, когда, в каких регионах страны и в каких масштабах административные ограничения рождаемости и внутренней миграции будут ослаблены или отменены. Власти наиболее многонаселенных и бедных штатов Индии, таких как Уттар-Прадеш, вероятно будут пытаться дополнять национальную политику благосостояния семьи мерами, непосредственно направленными на снижение рождаемости. Пронаталистская демографическая политика в Японии и Южной Корее, где СКР в настоящее время являются одними из наиболее низких в мире, постепенно становится более активной [Suzuki 2012]. Перспективы государственной демографической политики в России будут во многом определяться состоянием государственных финансов, однако, по мере привыкания населения к мерам экономической поддержки рождаемости, отказываться от них будет в силу политических причин все труднее.

Стремительное ослабление государственного административного контроля над демографическим поведением индивида в Западной Европе в 1970-е годы (либерализация разводов, отмена ограничений на пропаганду и распространение контрацепции, либерализация юридических норм, регулирующих производство аборта) было воспринято многими исследователями как начало общепланетарной тенденции к уходу государства из демографической сферы. Реальная картина была и, скорее всего, останется более сложной и мозаичной. Европейский вариант развития событий оказался важной, но не единственной тенденцией в общепланетарном потоке событий. Более того, в силу многочисленности населения азиатских и африканских стран наличие или отсутствие в них эффективной демографической политики окажет более мощное влияние на численность и структуру мирового населения, чем эволюция семейной политики на европейском континенте. 


\section{ВРЕМЕННЫЕ ЕДИНИЦЫ АНАЛИЗА: КОРОТКИЕ И ДЛИННЫЕ}

В исторической и социологической науке интервалами большой длительности оперируют представители как формационного, так и цивилизационного подходов. Споры между ними обычно не переходят в дискуссию о том, какие временные интервалы анализа - длинные или короткие - важнее для постижения истории, скорее, речь, как, например, у Ф. Броделя [1977], идет о том, как лучше использовать те и другие «по назначению».

Ситуация, сложившаяся сегодня в демографии, в этом отношении специфична здесь сторонники парадигмы однолинейного развития настаивают на неоспоримых, с их точки зрения, преимуществах длинных временных интервалов анализа над короткими. Временной аспект анализа при этом перекликается, как это часто бывает, с пространственным: для того, чтобы непослушная эмпирика не мешала высокой теории, используются две стратегии - укрупнение либо территориальных единиц анализа (в пределе - до масштабов планеты в целом), либо временных (в пределе - до интервалов протяженностью в несколько тысяч лет).

Иллюстрацией сказанного является полемика вокруг результатов Принстонского проекта «Европейская рождаемость» [Coale, Watkins. 1986]. Этот проект, позволивший исследовать процесс снижения рождаемости в европейских микрорегионах, не подтвердил одну из ключевых гипотез теории демографического перехода - об обусловленности снижения рождаемости предшествующим ему снижением смертности. Однако сторонники теории демографического перехода возразили в ответ, что интервалы анализа, использованные в принстонском проекте, были слишком короткими.

Как утверждает один из авторов, «хотя ни одна из крупномасштабных теорий перехода в области рождаемости не обсуждала до сих пор вопрос о том, какую именно шкалу времени данная теория намеревается использовать, эмпирическая проверка теорий неизбежно связана с выбором подобной шкалы. Исследования, использовавшие шкалу с десятилетними делениями (decadal scale), в частности, принстонский проект, приводят к дезориентирующим результатам, поскольку данный масштаб не позволяет увидеть опережения и запаздывания в процессах социальных и демографических изменений... Избрав десятилетние временные интервалы и используя концептуальный каркас исследования, основанный на методах регрессии, проект неявно предполагал, что влияние экономической модернизации на рождаемость проявится немедленно, безотносительно других условий» [Mason 1997: 448-449].

Предпочтение, отдаваемое сторонниками однолинейной парадигмы когортному методу, основано на той же методологической идее. Поскольку «демографическая система» развивается, как они считают, по своим, в значительной степени автономным от внешней среды законам [Вишневский 1982], для понимания этих законов необходимо устранить ее влияние на демографические показатели. Одним из способов сделать это является анализ итоговой рождаемости в когортах, например, [Демографическая... 2006]. Поскольку каждая когорта, особенно в нестабильных обществах, проходит через «хорошие» и «плохие» времена, итоговый показатель для когорты представляет собой среднюю величину, в которой уже не видно влияния экономической и политической турбулентности. 
Радикальное развитие этой идеи содержит статья Т. Соботки и В. Лутца. Авторы говорят, что СКР для условного поколения дает политикам дезориентирующие сигналы и предлагают отказаться от его использования «при общении с аудиторией недемографов, которая почти неизбежно истолкует его как когортный показатель» [Соботка, Лутц 2011: 456]. «Мы не смогли, - продолжают Соботка и Лутц, - придумать политически значимого вопроса, для ответа на который мы выбрали КСР ${ }^{6}$ [там же: 464]. Данный тезис вызывает недоумение, поскольку один из таких вопросов как раз и рассмотрен в «Европейских демографических таблицах 2012» [European... 2012], в подготовке которых принимал участие и Т. Соботка. Названная публикация содержит интересный раздел, посвященный влиянию экономической рецессии 2008-2010 гг. на рождаемость. Основным инструментом анализа в этом разделе выступает именно СКР для условного поколения.

Как полагают Соботка и Лутц, «если, например, вводится новая система отпусков по уходу за ребенком, - то мало кто из политиков, рассчитывающих, что это может положительно повлиять на рождаемость, был бы доволен узнать, что это влияние может сохраняться только пару лет, потому что оно, в первую очередь, отразится в изменении календаря, что и приведет к повышению КСР. То же, на что они, скорее всего, рассчитывали, это долгосрочный подъем уровня рождаемости («интенсивности»)» [Соботка, Лутц 2011: 464]. С данным тезисом также трудно согласиться. Во-первых, чтобы узнать, сколько лет («пару» или больше) «будет сохраняться это влияние», необходимо располагать данными о СКР или хотя бы о числе рождений за календарные годы, последовавшие за введением мер демографической политики. Во-вторых, у политики свои ритмы, задаваемые избирательными циклами. Последние, как правило, составляют от 2 до 6 лет, и политикам вряд ли совсем уж безразлично, придется ли на период избирательной кампании подъем рождаемости или ее спад. Для размышлений на эту тему опять-таки небесполезно вооружиться статистикой, приуроченной к календарным годам и описывающей длительность эффектов, наблюдавшихся в сходных ситуациях ранее.

В целом же когортные показатели политически ничуть не стерильнее показателей для условного поколения. Последние действительно позволяют приписать действующему политическому руководству успехи или неудачи, вызванные (как правило, только частично) политикой его предшественников. Но и когортные показатели в этом отношении небезупречны - полученная с их помощью средняя из показателей для «плохих» и «хороших» времен - вполне удобный инструмент для размазывания и размывания политической ответственности.

Демографы справедливо призывают избегать ошибочных выводов, связанных с абсолютизацией показателей, рассчитанных для условного поколения. Стоит ли, однако, впадать в другую методологическую крайность и преувеличивать возможности когортных показателей? На мой взгляд, старое доброе правило «не существует показателей, пригодных на все случаи жизни» остается в силе.

\footnotetext{
${ }^{6}$ Коэффициент суммарной рождаемости (КСР) и суммарный коэффициент рождаемости (СКР) - два названия одного и того же показателя, именуемого в англоязычной литературе total fertility rate.
} 


\section{ЗАКЛЮЧИТЕЛЬНЫЕ ЗАМЕЧАНИЯ}

В статье предпринята попытка показать, что игнорирование цивилизационных различий и региональных особенностей препятствует формированию реалистической картины демографического прошлого, настоящего и будущего. Из этого, разумеется, не следует, что парадигма однолинейного развития должна быть отправлена в отставку. Видение мира как совокупности изолированных и живущих исключительно по своим внутренним законам цивилизаций, равно как и жесткий формационный детерминизм уходят в прошлое вместе с «гранд-теориями» XIX и первой половины XX века. Мне лишь хотелось подчеркнуть, что доминирование в демографии парадигмы однолинейного развития ведет к неоправданной теоретической редукции, обедняющей картину «демографической вселенной».

Характерные черты подобной редукции хорошо известны. Цивилизационные и региональные особенности объявляются недостойными внимания теоретиков «мелочами», страновые нарративы (или, если угодно, кейс-истории) - предметом беллетристики, а не науки. Временные единицы анализа расширяются до таких пределов, что «мелочей», подобных региональным и даже глобальным экономическим и политическим кризисам, уже не видно. Любые действия, направленные на улучшение ситуации в конкретной стране или регионе, объявляются заведомо бессмысленными в случае, если они противоречат «генеральной линии» глобального развития, которая предполагается не просто изначально заданной, но еще и известной данной группе теоретиков. Как правило, эта линия видится в постепенном превращении не Запада в Запад. Отсутствие убедительных подтверждений данной тенденции в настоящем компенсируется заявлениями о том, что они непременно последуют в будущем. Как справедливо замечает Б. Витрок, «это не самый удачный метод» [Wittrock 2000: 33]. Контр-тенденции, такие, как the Rise of «the Rest» - “подъем остальных" [Amsden 2001; Zakaria 2008] и, прежде всего, усиление экономической и политической мощи Китая и Индии, равно как и «третий демографический переход» [Коулмен 2007], игнорируются. Не думаю, что перспективы демографии в XXI веке связаны с подобной теоретической редукцией.

Однако каковы эти перспективы? Хотя будущее развитие демографии может осуществляться по различным сценариям, в завершение статьи хотелось бы ограничиться лишь одним из них - тем, что представляется автору наиболее оптимистичным. Недавний всемирный опрос демографов [van Dalen, Henkens 2012] показал, что, по мнению большинства, статус ученого в демографии определяется, прежде всего, его достижениями в проведении эмпирических исследований. Феномен «зависимости от колеи» силен во всех человеческих сообществах, и демография, вероятно, останется в высокой степени эмпирической дисциплиной. Эмпирические исследования, всегда чуткие к злобе дня, будут так или иначе отражать новые тенденции XXI века - процессы, происходящие в незападных обществах, их растущее влияние на глобальное развитие, переходные и синкретические феномены, возникающие при взаимодействии Запада и не Запада. Это, в свою очередь, приведет к сдвигу в парадигмальном балансе демографической теории и будет способствовать более адекватному отражению процессов, происходящих за пределами западного мира. 


\section{ЛИТЕРАТУРА}

Бродель Ф. (1977). История и общественные науки. Историческая длительность // Философия и методология истории / Под ред. И.С. Кона. М.: Прогресс.

Вишневский А.Г. (1982). Воспроизводство населения и общество: история, современность, взгляд в будущее. М.: Финансы и статистика

Вишневский А.Г. (2012). Есть ли альтернативы у безальтернативного // Общественные науки и современность. № 2: 78-91.

Демографическая модернизация России (2006) / Под ред. А.Г.Вишневского. М.: Новое издательство.

Клупт М.А. (2008). Демография регионов Земли. СПб.: Питер.

Клупт М.А. (2010). Демографическая повестка XXI века: теории и реалии // Социологические исследования. №8: 60-71.

Клупт М.А. (2012). Страны Запада: будущее мультикультурализма в зеркале занятости // Мировая экономика и международные отношения. №7: 16-25.

Клупт М.А. (2013). Демографическое развитие России: нефтяной нарратив // Социологические исследования. №5: 56-66.

Коулмен Д. (2007). Иммиграции и этнические сдвиги в странах с низкой рождаемостью третий демографический переход в действии // Миграции и развитие: Доклады и статьи ведущих секций и докладчиков международной конференции «Миграция и развитие», Москва, 13-15 сентября 2007 г. М.: Би Эль Принт: 12 - 48.

Мартинелли А. (2006). Глобальная модернизация. Переосмысляя проект современности. СПб.: Издательство Санкт-Петербургского университета.

Парсонс Т. (1998). Система современных обществ / Пер. с англ. М.: Аспект Пресс.

Ситуация с рождаемостью. База данных ФОМ. 28.04.2011. URL: http://bd.fom.ru/report/map/d111719 (дата обращения: 04.10.2012).

Соботка Т., В. Лутц (2011). Коэффициент суммарной рождаемости дает политикам дезориентирующие сигналы: не следует ли отказаться от использования этого показателя? // Экономический журнал Высшей школы экономики. №4: 444-471.

Фуко М. (2003). Правительственность (идея государственного интереса и ее генезис) // Логос. № 39 (4-5): 1-22

Фукуяма Ф. (2007). Конец истории и последний человек. М.: Алгоритм.

Amsden A. (2001). The rise of «the rest»: challenges to the West from late-industrializing economies. Oxford.

Barnwal A. (2004). Success of the Indonesian population program: Lessons for India // Journal of Development and Social Transformation. 1: 43-49.

Bureau of Labor Statistics. Labor Force Statistics from the Current Population Survey. URL: http://www.bls.gov/cps/cpsaat39.pdf; http:// www.bls.gov/cps/cpsaat11.pdf (дата обращения: 22.03.2012).

Castiglioni M., G. Dalla Zuanna (2009). Marital and reproductive behavior in Italy after 1995: Bridging the gap with Western Europe? // European Journal of Population. 25(2): 1-26.

Coale A., S. Watkins, eds. (1986). The Decline of Fertility in Europe. Princeton: Princeton University Press. 
Coleman D. (2004). Why we don't have to believe without doubting in the «Second Demographic Transition» - some agnostic comments // Vienna Yearbook of Population Research: 11-24.

Eisenstadt S. (2000). Multiple modernities // Daedalus. 129(1): 1-29.

European Demographic Data Sheet 2012. Wittgenstein Centre for Demography and Global Human Capital. URL:

http://www.oeaw.ac.at/vid/datasheet/download/European_Demographic_Data_Sheet_2012.p df (дата обращения: 10.04.2014).

Greenhalgh S. (2003). Science, Modernity and China's one child policy // Population and Development Review. 29(2): 163-196.

Greenhalgh S., E. Winkler, eds. (2005). Governing China's population: From Leninist to neoliberal biopolitics. Stanford: Stanford University Press.

Lesthaeghe R., D.J. van de Kaa (1986). Twee demografische transities // R. Lesthaeghe, D.J. van de Kaa, eds. Bevolking -Groei en Krimp, Mens en Maatschappij. Deventer: Van Loghum Slaterus.

Lesthaeghe R., L. Neidert (2006). The second demographic transition in the U.S.: spatial patterns and correlates // Report 06 - 592, March. Population Studies Center, University of Michigan.

Lesthaeghe R., L. Neidert (2009). US presidential elections and the spatial pattern of the second demographic transition // Population and Development Review. 35(2): 391-400.

Lesthaeghe R. (2010). The Unfolding Story of the Second Demographic Transition // Population and Development Review. 36(2): 211-251.

Mason K. (1997). Explaining fertility transition // Demography. 34(4): 443-454

McNicoll G. (2009). Legacy, policy, and circumstance in fertility transition // Population and Development Review. 35(4): 777-795.

McNicoll G. (2011). Achievers and laggards in demographic transition: a comparison of Indonesia and Nigeria // Population and Development Review. 37 (supplement): 191-214.

Mouzelis N. (1997). Modernity: a non-European conceptualization / C. Keyder, ed. Tradition in modernity. Southern Europe in question. Istanbul: 25 - 44.

Office for National Statistics (2011a). Statistical Bulletin, 18, May 2011. Population Estimates by Ethnic Group 2002-2009.

Office for National Statistics (2011b). Labour Market Statistics, November 2011, (last updated February 2011). URL: http://www.ons.gov.uk/ons/publications/re-referencetables.html?edition=tcm\%3A77-222445 (дата обращения 22.03.2014).

Schmidt V. (2006). Multiple modernities or varieties of modernity? // Current Sociology. 54(1): 77-96.

Sheck D. (2006). Chinese family research. Puzzles, progress, paradigms and policy implications // Journal of family issues. 27(3): 275-284.

Suzuki T. (2012). Low fertility and governmental intervention in Japan and Korea // The Japanese journal of population. 10(1): 60-77.

The Indian States and Territories (2013). URL:

http://unidow.com/india\%20home\%20eng/statewise_gdp.html (дата обращения: 22.03.2013). 
Trajectoires et Origines (2010). Enquête sur la diversité des populations en France. Premiers résultats // INED, INSEE, Document de travail 168. Octobre $2010: 56$.

U.S. Census Bureau (2011). Overview of Race and Hispanic Origin: 2010 Census Brief. Issued March 2011.

Van Dalen H., K. Henkens (2012). What is on a demographer's mind? A worldwide survey // Demographic Research. 26(16): 363-408. URL: http://www.demographicresearch.org/Volumes/Vol26/16/ (дата обращения: 11.04.2014).

Van de Kaa D.J. (1996). Anchored narratives: the story and findings of half a century of research into the determinants of fertility // Population Studies. 50(3): 389-432.

Wittrock B. (2000). Modernity: One, none, or many? European origins and modernity as a global condition // Daedalus. 129(1): 31-60.

World Bank (2013). GDP per capita PPP (Current International \$) URL:

http://data.worldbank.org/indicator/NY.GDP.PCAP.PP.CD (дата обращения: 22.03.2013).

Zakaria F. (2008). The Post-American world. London: The Penguin Group. 


\title{
PARADIGMS AND OPPOSITIONS OF MODERN DEMOGRAPHY
}

\author{
$\underline{\text { MIKHAIL KLUPT }}$
}

Mikhail A. Klupt. Faculty of Humanities, St. Petersburg State Economic University. Russia. E-MAIL: klupt@mail.ru. DATE RECEIVED: JANUARY 2014.

\begin{abstract}
The paper aims to develop demographic theory by means of methodological reflection. Three principal oppositions of demographic theory are considered: the West and "the Rest"; the state and the individual; long-term and short-term trends. The paper argues for transforming demography from a mono-paradigmatic to a multi-paradigmatic science similar to sociology. Such conventional wisdoms of present-day demography as the withdrawal of the state from the demographic arena and the spread of the second demographic transition (SDT) beyond Western countries are challenged. It is shown that the successes and the failures of the state in China, Indonesia, India and Nigeria have influenced the size and the geographical distribution of the world's population to a greater extent than the SDT in the Western countries. The close negative correlation between life expectancy at birth and the percentage of extra-marital births in the regions of Russia is revealed. This shows that extra-marital fertility in Russia is caused not only by the SDT but also, to a great extent, by various social pathologies. In addition, the share of the world population involved in the SDT is decreasing due to rapid population growth in less developed countries and the slow pace of immigrant minorities' integration into Western societies. In contrast to Greenhalgh, who employed Foucault's concept of governmentality to show the Western roots of China's one-child policy, the paper argues that different types of governmentality result in different types of population policy. It is stressed that demography should pay more attention to the singularities of the state's role in diverse non-Western societies and to the effects that arise from the interaction of "SDT values" with non-Western institutions.
\end{abstract}

Keywords: demographic change; multiple modernities; second demographic transition; the state; governmentality; population policy.

\section{REFERENCES}

Amsden A. (2001). The rise of «the rest»: challenges to the West from late-industrializing economies. Oxford.

Barnwal A. (2004). Success of the Indonesian population program: Lessons for India // Journal of Development and Social Transformation. 1: 43-49.

Braudel F. (1977). Istoriya i obshhestvennye nauki. Istoricheskaya dlitel'nost' [History and social sciences] // Kon I.S., ed. Filosofiya i metodologiya istorii [Philosophy and methodology of history]. Moskva: Progress.

Bureau of Labor Statistics. Labor Force Statistics from the Current Population Survey. URL: http://www.bls.gov/cps/cpsaat39.pdf; http:// www.bls.gov/cps/cpsaat11.pdf (accessed: 22.03.2012).

Castiglioni M., G. Dalla Zuanna (2009). Marital and reproductive behavior in Italy after 1995: Bridging the gap with Western Europe? // European Journal of Population. 25(2): 1-26.

Coale A., S. Watkins, eds. (1986). The Decline of Fertility in Europe. Princeton: Princeton University Press. 
Coleman D. (2004). Why we don't have to believe without doubting in the «Second Demographic Transition» - some agnostic comments // Vienna Yearbook of Population Research: 11-24.

Coleman D. (2007). Immigratsii i ehtnicheskie sdvigi v stranakh s nizkoj rozhdaemost'yu - tretij demograficheskij perekhod $\mathrm{v}$ dejstvii? [Immigration and ethnic changes in low-fertility. countries - a third demographic transition in progress?] // Migratsii i razvitie: Doklady i stat'i vedushhikh sektsij i dokladchikov mezhdunarodnoj konferentsii «Migratsiya i razvitie», Moskva, 13-15 sentyabrya 2007 g. Moskva: Bi El Print: 12 - 48.

Eisenstadt S. (2000). Multiple modernities // Daedalus. 129(1): 1-29.

European Demographic Data Sheet 2012. Wittgenstein Centre for Demography and Global Human Capital. URL:

http://www.oeaw.ac.at/vid/datasheet/download/European_Demographic_Data_Sheet_2012.p df (accessed: 10.04.2014).

Foucault M. (2003). Pravitel'stvennost' (ideya gosudarstvennogo interesa i ee genezis)

[Govermentality (idea of the state's interest and its genesis] // Logos. № 4-5 (39): 1-22.

Fukuyama F. (2007). Konets istorii i poslednij chelovek [The end of history and the last man]. Moskva: Algoritm.

Greenhalgh S. (2003). Science, Modernity and China's one child policy // Population and Development Review. 29(2): 163-196.

Greenhalgh S., E. Winkler, eds. (2005). Governing China's population: From Leninist to neoliberal biopolitics. Stanford: Stanford University Press.

Klupt M.A. (2008). Demografiya regionov Zemli [Demography of the world regions]. SanktPeterburg: Piter.

Klupt M.A. (2010). Demograficheskaya povestka XXI veka: teorii i realii [Demographic agenda of the XXI century: theories and realities] // Sotsiologicheskie issledovaniya [Sociological studies]. №8: 60-71.

Klupt M.A. (2012). Strany Zapada: budushhee mul'tikul'turalizma v zerkale zanyatosti [West countries: the future of multiculturalism in the mirror of employment] // Mirovaya ehkonomika i mezhdunarodnye otnosheniya [World economy and international relations]. №7: 16-25.

Klupt M.A. (2013). Demograficheskoe razvitie Rossii: neftyanoj narrativ [Demographic change in Russia: oil narrative] // Sotsiologicheskie issledovaniya [Sociological studies]. №5: 56-66.

Lesthaeghe R., D.J. van de Kaa (1986). Twee demografische transities // R. Lesthaeghe, D.J. van de Kaa, eds. Bevolking -Groei en Krimp, Mens en Maatschappij. Deventer: Van Loghum Slaterus.

Lesthaeghe R., L. Neidert (2006). The second demographic transition in the U.S.: spatial patterns and correlates // Report 06 - 592, March. Population Studies Center, University of Michigan.

Lesthaeghe R., L. Neidert (2009). US presidential elections and the spatial pattern of the second demographic transition // Population and Development Review. 35(2): 391-400.

Lesthaeghe R. (2010). The Unfolding Story of the Second Demographic Transition // Population and Development Review. 36(2): 211-251.

Martinelli A. (2006). Global'naya modernizatsiya. Pereosmyslyaya proekt sovremennosti [Global modernization. Rethinking the project of modernity]. Sankt-Peterburg: Izdatel'stvo SanktPeterburgskogo universiteta. 
Mason K. (1997). Explaining fertility transition // Demography. 34(4): 443-454

McNicoll G. (2009). Legacy, policy, and circumstance in fertility transition // Population and Development Review. 35(4): 777-795

McNicoll G. (2011). Achievers and laggards in demographic transition: a comparison of Indonesia and Nigeria // Population and Development Review. 37 (supplement): 191-214.

Mouzelis N. (1997). Modernity: a non-European conceptualization / C. Keyder, ed. Tradition in modernity. Southern Europe in question. Istanbul: 25 - 44.

Office for National Statistics (2011a). Statistical Bulletin, 18, May 2011. Population Estimates by Ethnic Group 2002-2009.

Office for National Statistics (2011b). Labour Market Statistics, November 2011, (last updated February 2011). URL: http://www.ons.gov.uk/ons/publications/re-referencetables.html?edition=tcm\%3A77-222445 (accessed: 22.03.2014).

Parsons T. (1998). Sistema sovremennykh obshhestv [The system of modern societies]. Moskva: Aspekt Press.

Schmidt V. (2006). Multiple modernities or varieties of modernity? // Current Sociology. 54(1): 77-96.

Sheck D. (2006). Chinese family research. Puzzles, progress, paradigms and policy implications // Journal of family issues. 27(3): 275-284.

Situatsiya s rozhdaemost'yu. Baza dannykh FOM. 28.04.2011. [Fertility situation. FOM database]. URL: http://bd.fom.ru/report/map/d111719 (accessed: 04.10.2012).

Sobotka T., W. Lutz (2011). Koehffitsient summarnoj rozhdaemosti daet politikam dezorientiruyushhie signaly: ne sleduet li otkazat'sya ot ispol'zovaniya ehtogo pokazatelya? [Misleading policy message from period TFR: should we stop using it?] // Ehkonomicheskij zhurnal Vysshej shkoly ehkonomiki. №4: 444-471.

Suzuki T. (2012). Low fertility and governmental intervention in Japan and Korea // The Japanese journal of population. 10(1): 60-77.

The Indian States and Territories (2013). URL: http://unidow.com/india\%20home\%20eng/statewise_gdp.html (accessed: 22.03.2013).

Trajectoires et Origines (2010). Enquête sur la diversité des populations en France. Premiers résultats // INED, INSEE, Document de travail 168. Octobre 2010 : 56.

U.S. Census Bureau (2011). Overview of Race and Hispanic Origin: 2010 Census Brief. Issued March 2011.

Van Dalen H., K. Henkens (2012). What is on a demographer's mind? A worldwide survey // Demographic Research. 26 (16): 363-408. URL: http://www.demographicresearch.org/Volumes/Vol26/16/ (accessed: 11.04.2014).

Van de Kaa D.J. (1996). Anchored narratives: the story and findings of half a century of research into the determinants of fertility // Population Studies. 50(3): 389-432.

Vishnevskij A.G. (1982). Vosproizvodstvo naseleniya i obshhestvo: istoriya, sovremennost', vzglyad v budushhee [Population reproduction and society: history, modernity and view in the future]. Moskva: Finansy i statistika.

Vishnevskij A.G. (2012). Est' li al'ternativy u bezal'ternativnogo [Are there alternatives to the choiceless?] // Obshhestvennye nauki i sovremennost' [Social sciences and modernity]. № 2: 78-91. 
Vishnevskij A.G., ed. (2006). Demograficheskaya modernizatsiya Rossii [Demographic modernization of Russia]. Moskva: Novoe izdatel'stvo.

Wittrock B. (2000). Modernity: One, none, or many? European origins and modernity as a global condition // Daedalus. 129(1): 31-60.

World Bank (2013). GDP per capita PPP (Current International \$) URL:

http://data.worldbank.org/indicator/NY.GDP.PCAP.PP.CD (accessed: 22.03.2013).

Zakaria F. (2008). The Post-American world. London: The Penguin Group. 